\title{
Examining toxic metals contamination, speciation and geochemistry of soil impacted by open disposal of waste cathode ray tubes in Nigeria
}

\author{
Paschal Okiroro INIAGHE ${ }^{1,2}$ and Gilbert Umaye ADIE ${ }^{1 *}$ \\ ${ }^{1}$ Department of Chemistry, Faculty of Science, University of Ibadan, Ibadan, Nigeria \\ ${ }^{2}$ Department of Chemistry, Faculty of Science, Federal University Otuoke, Nigeria
}

\begin{abstract}
In this study, soil contamination by toxic metals released from cathode ray tubes (CRTs) openly discarded within the vicinities of artisans' workshops in Nigeria was assessed in order to ascertain the metal leaching potential of CRTs, mobility and bioavailability of the leached metals in soil. Furthermore, the ecological geochemistry of the impacted soils was carried out. Seventy soil samples were randomly collected from thirty five locations at depths $0-15 \mathrm{~cm}$ (topsoil) and $15-30 \mathrm{~cm}$ (sub-soil), respectively from two selected states each within five geographical regions of Nigeria. Environmentally available lead $(\mathrm{Pb})$, cadmium $(\mathrm{Cd})$, chromium $(\mathrm{Cr})$, nickel $(\mathrm{Ni})$ and copper $(\mathrm{Cu})$ were extracted from dried and sieved soil samples using aqua regia solution and were analyzed using flame atomic absorption spectrometry (AAS). Additionally, the metals were also sequentially extracted into five fractions and their concentrations determined using AAS. Concentration of $\mathrm{Pb}$ ranged from $0.4-6510 \mathrm{mg} / \mathrm{kg}$ with all top-soils exceeding the Nigerian NESREA regulatory limit of $164 \mathrm{mg} / \mathrm{kg}$ while $\mathrm{Cd}, \mathrm{Cr}, \mathrm{Ni}$ and $\mathrm{Cu}$ levels were within their respective regulatory limits. Geoaccumulation index values indicated that approximately $83 \%$ of all top-soils represented strong to extreme contamination by $\mathrm{Pb}$ while sequential extraction showed that majority of the extracted $\mathrm{Pb}$ was in the Fe-Mn oxide, residual and exchangeable forms. The results generally suggest that CRT disposal areas are highly polluted with $\mathrm{Pb}$ with significant amounts in bioavailable phases. Thus, waste CRTs are required to be managed in an environmentally sound manner to forestall any probable harm to ecological functioning of such areas.
\end{abstract}

Keywords: cathode ray tube, leaching, toxic metals, geoaccumulation index, sequential extraction.

\section{Introduction}

The environment comprises the air, water, soil and biota. Maintaining the environment in a state as pristine as possible is a necessity owing to the importance of its components. However, urbanization, advances in technology, industrialization and modernization have resulted in an inevitable generation of wastes of various kinds at an alarming rate, which contribute to environmental contamination. One important waste stream that has attracted global attention in recent times is made up of substances generated from end-of-life (eol) Electrical and Electronic Equipment (EEE), simply called "e-waste". E-waste include a wide-range of EEE such as large household appliances (refrigerators, air conditioners, stereos and consumer electronics) and small household appliances (computers, monitors, televisions, etc.) [1]. This waste stream has been reported to be the fastest growing waste stream globally, at three times the rate of municipal solid waste [2].

One major component of the e-waste stream in Nigeria is the cathode ray tube (CRT) obtained mostly from discarded televisions and computer monitors. The presence of this category in the waste stream arises due to a transition from CRT-based devices to flat screen displays [3], transboundary movement of non-functional CRT devices into the country $[4,5]$ and decreased lifespan of used CRTs [6]. The major concern coming up from its presence in the environment is its high metal content, especially lead. Considering the fact that waste CRTs are commonly disposed of inappropriately (mostly stockpiled in the open), rainfall can cause leaching of metals from the glass into top- and sub-soil, causing contamination of soil, surface waters (due to surface run offs) and crops planted around such vicinities. Metal concentrations in soil are of importance due to their nonbiodegradability and bioaccumulative behavior, while their toxicities and bioavailabilities for plant uptake are dictated by their association with other soil components and the ability of the soil to release them [7].

Studies on toxic metal contamination in Nigerian soils due to leaching of several types of wastes abound with much emphasis on industrial areas, municipal dumpsites, e-waste recycling and burning sites, etc. [8 12]. However, there is paucity of data in literature on soil contamination due to metal leaching from discarded CRTs. The few cited studies in literature were concerned with metal leaching from CRT glass under simulated conditions where the glass was crushed into fine particles [13 - 15]. Therefore, this study was designed to evaluate contamination/ pollution status and chemical forms of metals in soil arising from open disposal of CRTs within artisans' workshops in Nigeria.

\footnotetext{
* Corresponding author. E-mail address: gildie1975@gmail.com (Gilbert Umaye Adie)
} 


\section{Experimental}

\subsection{Study area}

Nigeria is located on the west coast of Africa. It lies within latitude 9.082 and longitude 8.675 . The climatic condition varies in most parts of the country; in the North, it is arid and in the South, there is an equatorial type of climate. It shares boundaries with the Republics of Cameroon in the East, Benin and Niger in the West, Niger and Chad in the North and the Gulf of Guinea in the South. It has a total area of 923,768 square kilometer, housing approximately 180 million people consisting of 374 ethnic groups with Hausa, Igbo and Yoruba constituting the major languages.

The study area was categorized into five geographical regions and samples were collected from two selected states from each region. The regions and states in bracket were: South-South (SS - Delta and Bayelsa States), South-East (SE - Anambra and Abia States), South-West (SW - Lagos and Oyo States), North-Central (NC - Kogi and Abuja States) and North-West (NW - Kaduna and Kano States), respectively. The North-East region was not included in this study due to security concerns presently prevailing in that region. The selected States were considered because they are quite urbanized, and as a result, accessibility to artisans engaged in repair of ICT devices was easy. These artisans' workshops were randomly distributed throughout the selected locations. Of particular interest were artisans engaged in the repair of CRT-based devices. There was no waste management practice for end-of-life CRT-based devices by these artisans as this waste category was normally seen stockpiled beside/ in front of the workshops. A map of the study area is shown in Fig. 1 while Plate 1 is a pictorial representation of some of the artisans' workshop indicating the discarded CRTs.

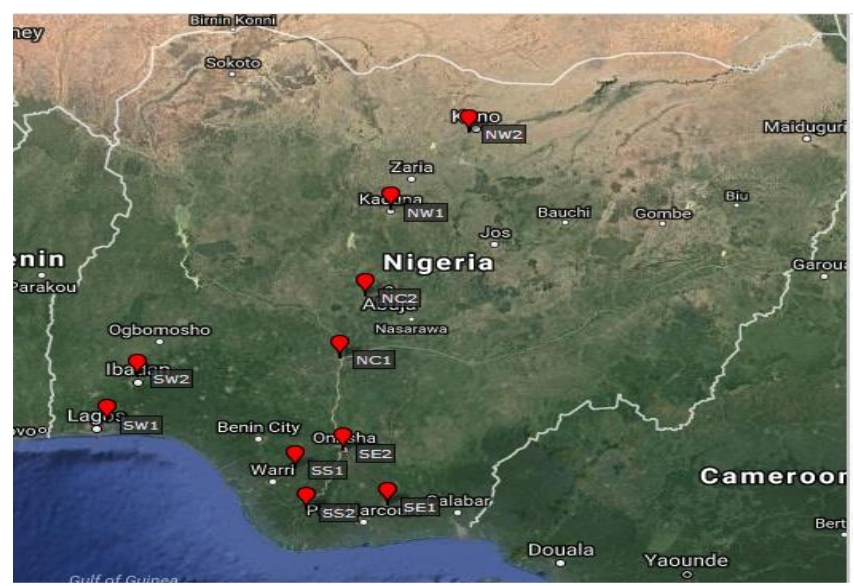

Figure 1. Map of study area, indicating sampling locations

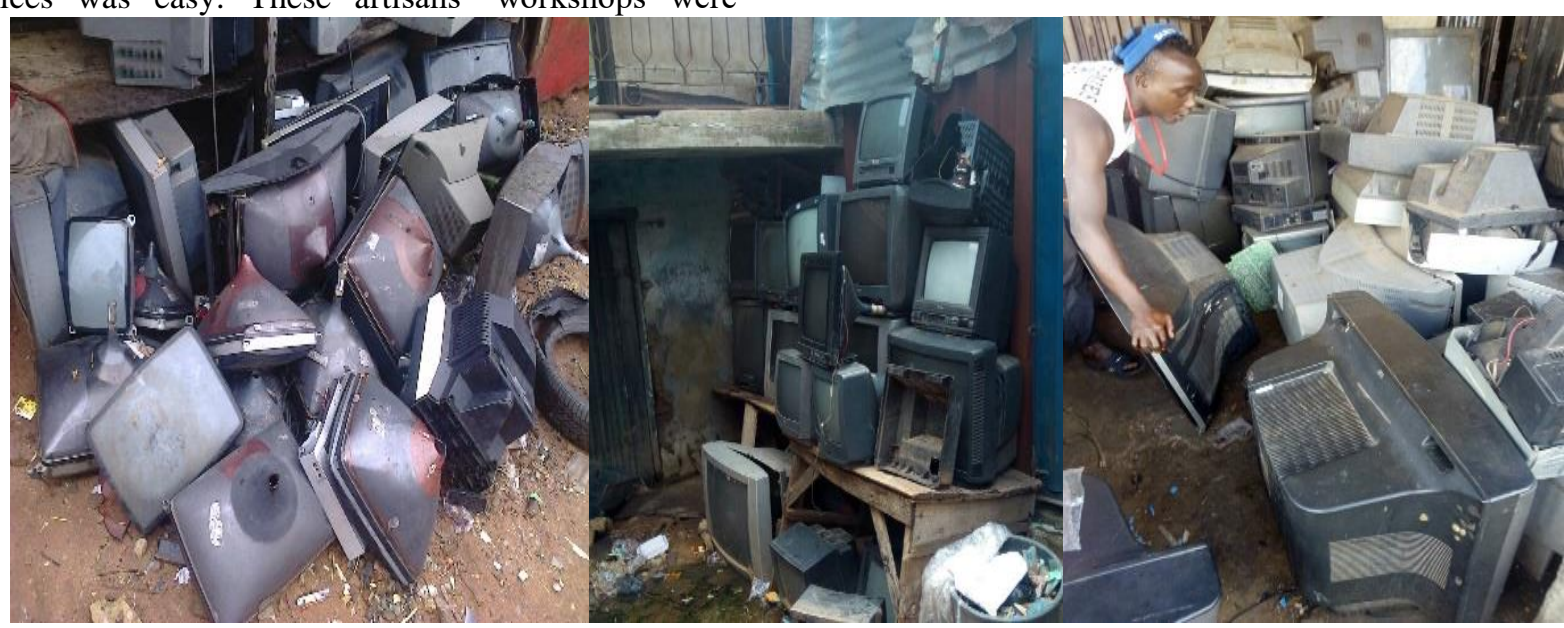

Plate 1. Some of the sampled area

\subsection{Soil sampling}

From each State within each of the five regions studied, a control sample was collected and two to three composites samples were collected from the study areas by means of a soil coral at depths $0-15 \mathrm{~cm}$ (top-soil) and $15-30 \mathrm{~cm}$ (sub-soil), respectively. The number of samples collected for compositing was dictated by accessibility to the soils. About three (3) to five (5) samples were collected from within and at designated distances from the center of the disposal areas for compositing. Fourteen (14) composite samples (seven locations) were thus collected from each region comprising ten (10) from study areas and four (4) control samples. A total of 70 samples were collected from the five geographical regions.

About $0.5 \mathrm{~kg}$ of soil samples were separately collected from the top and sub-soils into well-labelled polythene bags. The soils were air-dried at ambient temperature in the laboratory for two weeks and were sieved using a $2 \mathrm{~mm}$ mesh sieve. The $2 \mathrm{~mm}$ sieved soil samples were subsequently divided into two groups: the first group was for physicochemical parameters while the second group was for metals analyses. Samples for metal analyses were further size-reduced using agate mortar and pestle, sieved with $0.6 \mathrm{~mm}$ mesh sieve and stored in properly labelled polythene bags in a dry place until further preparation.

\subsection{Physicochemical characteristics of the soil \\ 2.3.1. Soil $p H$}

The $\mathrm{pH}$ of the soil-water solution for each sample was measured using a pocket-sized digital $\mathrm{pH}$ meter ( $\mathrm{pHep}{ }^{\circledR}$, Hanna Instrument, USA) which had earlier been calibrated with buffer solutions of $\mathrm{pH} 4$ and 7 respectively. The soils' $\mathrm{pH}$ values were determined in soil: deionized water solution (ratio 1:5) according to Rayment and Higginson [16]. 


\subsubsection{Total organic carbon}

Total organic carbon was determined using the Walkley and Black [17] wet oxidation method.

\subsection{Analysis of toxic metals}

Wet digestion method using a mixture of nitric acid (69\%, Fluka) and hydrochloric acid (37\%, Sigma) was used for metals extraction. Exactly $1.00 \mathrm{~g}$ of each soil sample was placed in a beaker, followed by the addition of $9 \mathrm{~mL} \mathrm{HCl}$ and $3 \mathrm{~mL} \mathrm{HNO}_{3}$ to form the digesting solution otherwise called aqua regia. This mixture was swirled to wet the sample, covered with a watch glass and allowed to stand overnight. The next day, the beaker was heated in the hood until the volume of acid mixture was reduced to about $5 \mathrm{~mL}$. The digest was filtered using Whatman No. 1 filter paper and made up to $25 \mathrm{~mL}$ with $0.25 \mathrm{M} \mathrm{HNO}_{3}$ [18].

Digested samples were analyzed for metals of environmental concern commonly used in CRT formulations, including lead $(\mathrm{Pb})$, cadmium $(\mathrm{Cd})$, chromium $(\mathrm{Cr})$, copper $(\mathrm{Cu})$ and nickel $(\mathrm{Ni})$ by Perkin Elmer AAnalyst 200 Atomic Absorption Spectrophotometer (Germany).

\subsection{Quality assurance/ Quality control}

Blanks were used to check method and reagent impurities. Analytical grade reagents were used for all analyses. All glassware and plastic ware were soaked in $5 \% \mathrm{HNO}_{3}$ overnight and rinsed with deionized water prior to use. Tools and work surfaces were carefully cleaned for each sample preparation during pulverization to avoid cross contamination. Samples were analyzed in duplicates to check for precision of the chosen method while blind samples were also sent for analysis to check the accuracy of the measuring instrument. Method validation was evaluated using the spiked recovery study. The spike recoveries for the various metals ranged from 92.6 to $104.3 \%$.

\subsection{Assessment of soil contamination}

\subsubsection{Geo-accumulation index (Igeo)}

A common approach for approximating the enrichment of metals above background levels is to calculate the geoaccumulation index (Igeo) proposed by Müller [19]:

$$
\text { Igeo }=\log _{2} \frac{C_{n}}{1.5 B_{n}}
$$

where:

- $\quad C_{n}$ is the measured concentration of element $(n)$ in the enriched soil sample;

- $\quad B_{n}$ is the background concentration from the control area for element $(n)$;

- $\quad 1.5$ is a factor introduced to minimize the effect of possible variations in the background value (correction factor) due to lithological variations.

\subsection{Statistical analysis}

Data were expressed as mean \pm standard deviation. In order to confirm the relationship among soil properties (physicochemical properties and metal content), principal component analysis (PCA) was applied to the generated data sets for identifying groups of metals that correlate, which can be considered as having a common source.

\subsection{Metal speciation studies}

Speciation analysis was conducted on soil samples which recorded metal levels above regulatory limits according to Tessier's five-step sequential extraction procedure [20]. This procedure was selected because it is well documented in literature to give detailed description of the available forms of metals in soils. The procedure was carried out with an initial weight of $1.00 \mathrm{~g}$ in $50 \mathrm{~mL}$ capacity centrifuge tubes.

\section{Results and discussion}

\subsection{Physicochemical characteristics of soil}

Summaries of the physicochemical characteristics of the studied soil samples are presented in Figs. 2 and 3, respectively. The average $\mathrm{pH}$ values (ranging from 6.44 - 9.75) show that the studied soils were predominantly alkaline except for SW soils, which were slightly acidic. All sub-soils except SE soils had higher $\mathrm{pH}$ values than top-soils (i.e. $\mathrm{pH}$ increased with depth) (Fig. 2). Similar $\mathrm{pH}$ trends have been previously reported for soils in various parts of Nigeria [9, 11, 21 - 23].

The percent TOC content in this study was found to range from 0.08 to $1.85 \%$ across all studied locations and depths. A decrease in the percent TOC from top to subsoil was observed in all studied regions (Fig. 3). The results of this study are consistent with the findings of Iwegbue et al. [24], Wali et al. [25] and Ojuri et al. [26] where a drop in percent organic carbon with depth was observed. Soil organic matter and $\mathrm{pH}$ are among major factors that can influence availability and retention of metals. The $\mathrm{pH}$ range of all soils suggest low leachability of metals to sub-soils as most metals within this $\mathrm{pH}$ range are not free, rather, they exist either as precipitates or complexes. The TOC normally contains humid materials which have the ability to hold back metals at top-soils. The low TOC content implies low retentive capacity of the metals.

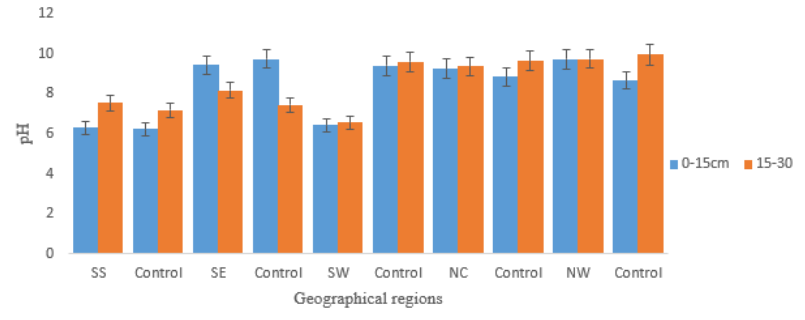

Figure 2. Comparison of the average $\mathrm{pH}$ values across the studied regions

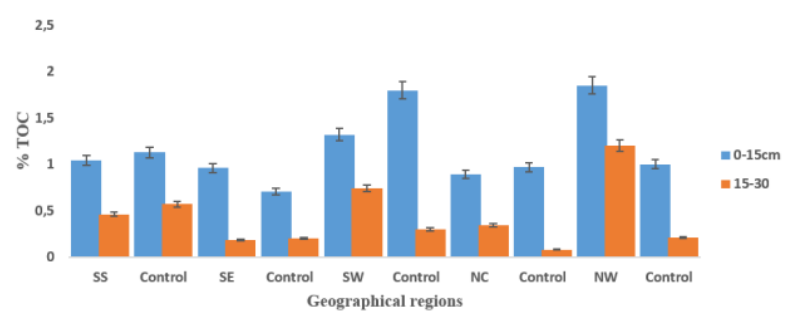

Figure 3. Comparison of the average percent total organic carbon across the studied regions 


\subsection{Toxic metal concentrations in soils}

The average metal concentrations in soil samples obtained from CRT disposal and control areas on regional basis are displayed in Figs. 4 - 8. Lead levels in experimental soil samples were in the following ranges: $0.39-6510 \mathrm{mg} / \mathrm{kg}$ from South-South (SS), $18.9-1180$ $\mathrm{mg} / \mathrm{kg}$ from South-East (SE), 15.3 - $328 \mathrm{mg} / \mathrm{kg}$ from South-West (SW), $1.20-269 \mathrm{mg} / \mathrm{kg}$ from North-Central (NC) and $9.40-1250 \mathrm{mg} / \mathrm{kg}$ from North-West (NW), respectively. Control soil samples showed relatively low levels of $\mathrm{Pb}$, ranging from $3.0-29.5 \mathrm{mg} / \mathrm{kg}$ across all locations and depths respectively. Of all the metals quantified, only $\mathrm{Pb}$ was detected at very high levels, which exceeded its regulatory limit set by the National Environmental Standards Regulations and Enforcement Agency, Nigeria [27].

Soil samples from SS showed a maximum concentration of $6510 \mathrm{mg} / \mathrm{kg}$. Many factors could be responsible for this. The CRTs from this region were found discarded without their plastic casings. Furthermore, this region experiences acid rain as a result of petroleum exploration activities. Acid rain has a tendency of influencing higher leachability of metals from the CRT glass. This is demonstrated from the lowest acidic $\mathrm{pH}$ indicated in soils from SS. The results presented in Fig. 4 reveal that all top-soils had higher mean $\mathrm{Pb}$ concentration compared with the sub-soils in all studied regions and hence, top soils were better indicators of metallic burdens [28]. The high $\mathrm{Pb}$ levels reported in this study are similar to the findings of Bridgen et al. [29] where CRTs were broken and openly discarded.

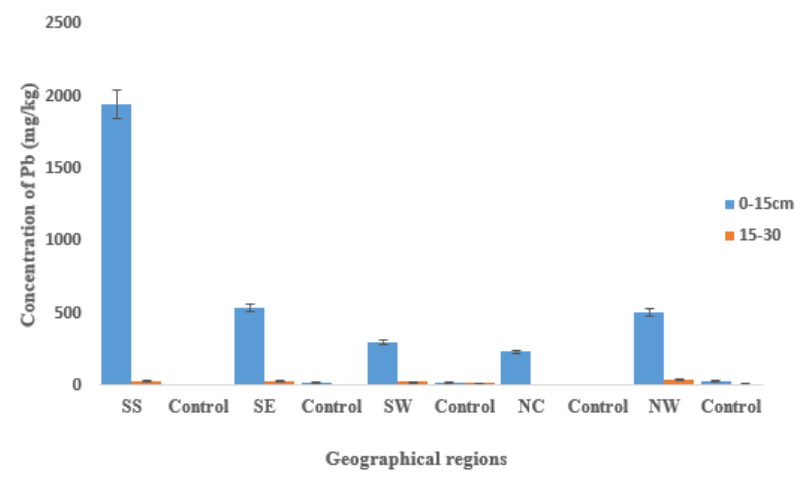

Figure 4. Comparison of average $\mathrm{Pb}$ levels in soil across studied regions and depths

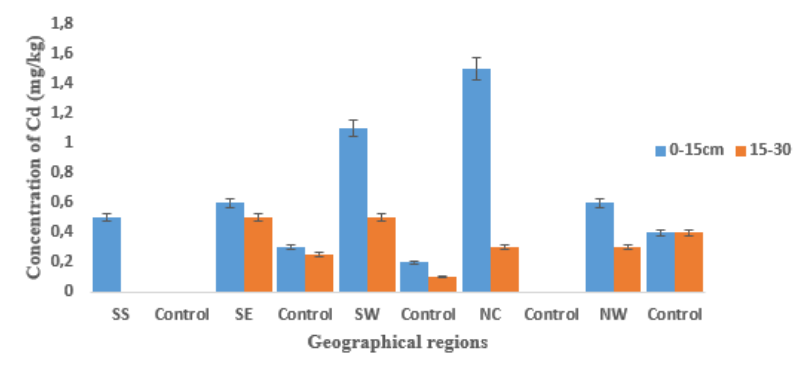

Figure 5. Comparison of average Cd levels in soil across studied regions and depths

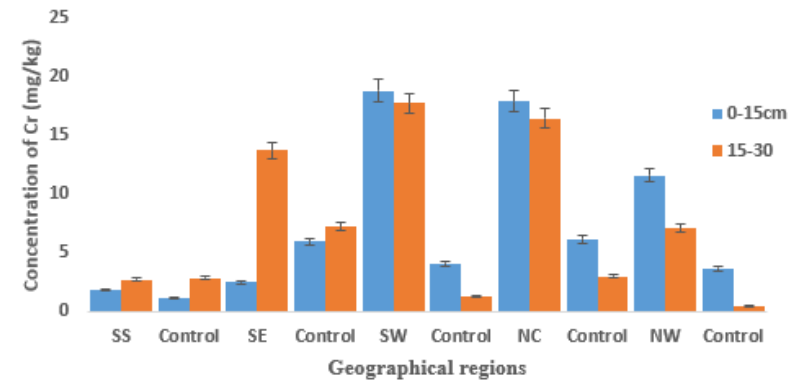

Figure 6. Comparison of average $\mathrm{Cr}$ levels in soil across studied regions and depths.

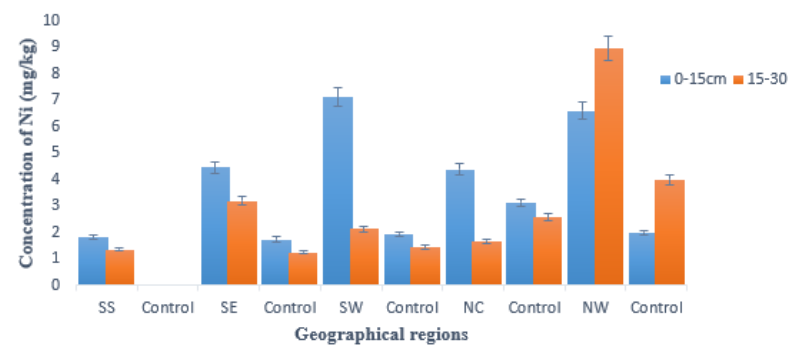

Figure 7. Comparison of average Ni levels in soil across studied regions and depths.

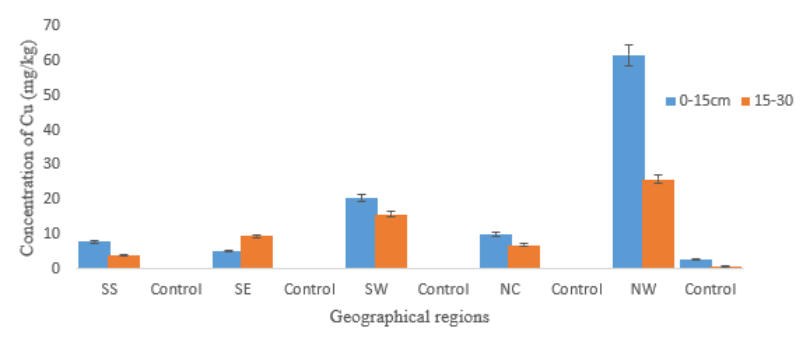

Figure 8. Comparison of average $\mathrm{Cu}$ levels in soil across studied regions and depths

Cadmium concentration in control soil samples ranged from $\mathrm{ND}-0.04 \mathrm{mg} / \mathrm{kg}$ while for experimental soil samples it ranged as follows: $\mathrm{ND}-0.55 \mathrm{mg} / \mathrm{kg}$ from SS, ND -1.50 $\mathrm{mg} / \mathrm{kg}$ from $\mathrm{SE}, 0.50-2.00 \mathrm{mg} / \mathrm{kg}$ from $\mathrm{SW}, \mathrm{ND}-1.50$ $\mathrm{mg} / \mathrm{kg}$ from $\mathrm{NW}$ and ND - $1.75 \mathrm{mg} / \mathrm{kg}$ from $\mathrm{NW}$ respectively. Like $\mathrm{Pb}$, Figs. 5, 6, 7 and 8 indicate that the top-soils generally had higher average $\mathrm{Cd}, \mathrm{Cr}$ (except SS and SE soils), Ni (except NC soils) and $\mathrm{Cu}$ (except SS and SE soils) levels in all studied locations. However, these metals were all within their respective NESREA [27] regulatory limits in soil, suggesting that the metal concentrations in soils within the premises of CRT disposal were not posing any significant hazard to human health and the environment. However, a little elevation in metal levels across the regions of the studied areas compared with the control is a sign that there was a form of some leaching of the metals from CRT glass.

\subsection{Assessment of toxic metals contamination in soil 3.3.1. Geoaccumulation index (Igeo)}

Geoaccumulation index (Igeo) values are displayed in Table 1. The Igeo for $\mathrm{Pb}$ in top-soils for all studied locations ranged from 2.4 to 8.2 (approximately $83 \%$, representing strong to extreme contamination by $\mathrm{Pb}$ ) and from -5.7 to 2.6 for sub-soils, indicating uncontamination to moderate contamination by $\mathrm{Pb}$. From Igeo analysis, about $23 \%$ of all top-soils analyzed were designated as being extremely contaminated. The mean Igeo for all 
sub-soils was less than 1 , implying a relative absence of $\mathrm{Pb}$ leaching down the soil profile. The Igeo of $\mathrm{Cd}$ ranged from $-3.9-2.7$, indicating uncontamination to moderate contamination by $\mathrm{Cd}$. With the exception of SW soils which showed a mean Igeo value of 1.3, all other soils determined had mean Igeo values less than 1, suggesting uncontamination of these soils by $\mathrm{Cd}$. The Igeo values for
$\mathrm{Cr}$ and $\mathrm{Ni}$ for all studied soils across all depths were less than 0 , absolutely specifying no contamination. The Igeo values for $\mathrm{Cu}$ showed that about $8 \%$ of the total sample population had values greater than 0 but less than 2 . Soils from these regions also recorded high Igeo values for $\mathrm{Pb}$ and $\mathrm{Cd}$, suggesting a probable common source of the metals.

Table 1. Range of geoaccumulation index (mean in parenthesis) of metals studied

\begin{tabular}{|c|c|c|c|c|c|c|}
\hline \multirow[b]{2}{*}{ Location } & \multirow[b]{2}{*}{ Depth (cm) } & \multicolumn{5}{|c|}{ Geoaccumulation index range } \\
\hline & & $\mathbf{P b}$ & Cd & $\mathrm{Cr}$ & $\mathbf{N i}$ & $\mathbf{C u}$ \\
\hline South & $0-15$ & $2.2-9.4(3.0)$ & $-1.6-0.4(0.8)$ & $-7.9--5.1(-6.5)$ & $-6.1--5.9(6.0)$ & $-5.8-1.9(-3.7)$ \\
\hline South & $15-30$ & $-3.4-3.7(0.6)$ & $-0.3-0.4(-0.03)$ & $-6.8-0(-3.6)$ & $-7.0--6.0(-6.5)$ & $-5.5--3.4(-4.4)$ \\
\hline South & $0-15$ & $1.8-5.2(3.5)$ & $-5.5-0(-3.5)$ & $-10.2-0(-5.3)$ & $-5.4--3.4(-4.7)$ & $-7.6--2.4(-4.9)$ \\
\hline East & $15-30$ & $1.3-2.6(2.1)$ & $0-0.4(0.08)$ & $-3.6-0(-.17)$ & $-6.5--2.6(-4.8)$ & $-4.5-0.5(-2.5)$ \\
\hline South & $0-15$ & $3.4-3.6(3.5)$ & $-0.5-1.4(0.3)$ & $-3.6-0(-2.5)$ & $-5.7-0(-3.8)$ & $-2.7-0(-1.6)$ \\
\hline West & $15-30$ & $2.1-3.0(2.9)$ & $-0.3-2.1(0.6)$ & $-3.7--2.7(-3.4)$ & $-5.7--4.7(-5.9)$ & $-3.1-1.7-(-2.3)$ \\
\hline North & $0-15$ & $3.7-4.9(4.3)$ & $-1.6-1.0(-0.1)$ & $-3.3-0(-2.1)$ & $-6.3-0(-3.9)$ & $-2.9-0(-1.9)$ \\
\hline Central & $15-30$ & $\begin{array}{l}-4.2--1.64(- \\
2.3)\end{array}$ & $-0.3-1.3(0.2)$ & $-3.5-0(-2.2)$ & $-6.9-0(-4.3)$ & $-4-0(-2.4)$ \\
\hline North & $0-15$ & $2.5-4.7(3.1)$ & $0-1.5(0.3)$ & $-5.6-0(-3.9)$ & $-5.6-0(-3.2)$ & $-4.3-1.2(-1.8)$ \\
\hline West & $15-30$ & $1.2-5(2.6)$ & $-0.3-0.7(0.4)$ & $-5.3--3.3(-4.6)$ & $-6.6-0(-3.3)$ & $-4-0.3(-1.9)$ \\
\hline
\end{tabular}

\subsection{Correlation studies}

\subsubsection{Principal Component Analysis (PCA)}

Results of PCA application for all sites and depths are presented in Figs. 9 and 10 respectively. At depth 0-15 $\mathrm{cm}$, three factors were obtained accounting for $65.2 \%$ of the total variance. Factor 1 was dominated by TOC, $\mathrm{Cd}$, $\mathrm{Cr}$ and $\mathrm{Ni}$, accounting for $27.7 \%$ of the total variance. This factor showed that metal complexation to organic matter was the predominant way of metals retention in soil [30, 31]. Factor 2 accounted for $24.1 \%$ of the total variance and was dominated by $\mathrm{EC}$ and $\mathrm{Pb}$, indicating that $\mathrm{Pb}$ had association with soil electrical conductivity. The open disposal of CRTs and the subsequent leaching of $\mathrm{Pb}$ from the leaded CRT glass was considered the main contributor to its presence in these soils as indicated by its very high concentration. Bipolarity of factor with higher loading of $\mathrm{pH}$ was observed. Factor 3 was dominated by high loading of $\mathrm{Cu}$ and accounted for $13 \%$ of the total variance. This factor suggested that $\mathrm{Cu}$ in some regions could have been present in the soil from other sources entirely different from those of other metals.

At $15-30 \mathrm{~cm}$ depth, three factors were also obtained accounting for $70.2 \%$ of the total variance. Factor 1 accounted for $40.2 \%$ of the total variance, and was dominated by TOC, $\mathrm{Pb}$ and $\mathrm{Ni}$. This factor indicated that complexation to organic matter was the prevailing way of retention of $\mathrm{Pb}$ and $\mathrm{Ni}$ in soils at this depth [30]. Factor 2 accounted for $15.4 \%$ of the total variance and was dominated by $\mathrm{Cd}$ and $\mathrm{Cu}$. Copper had higher loading of 0.866 , which might be explained by the chalcophilic characters of these metals i.e. they form sulfides which are poorly soluble minerals e.g. $\mathrm{Cu}_{2} \mathrm{~S}, \mathrm{CuS}$ and $\mathrm{CdS}$ [31]. Copper forms stronger organic complexes than other bivalent transition metals and therefore, soil rich in organic matter can retain more copper [32]. Factor 3 accounted for $14.5 \%$ of the total variance and was dominated by $\mathrm{Cr}$, suggesting that this metal could come from sources different from those of other metals. Bipolarity of factor with a high negative loading for $\mathrm{pH}$ was also observed.

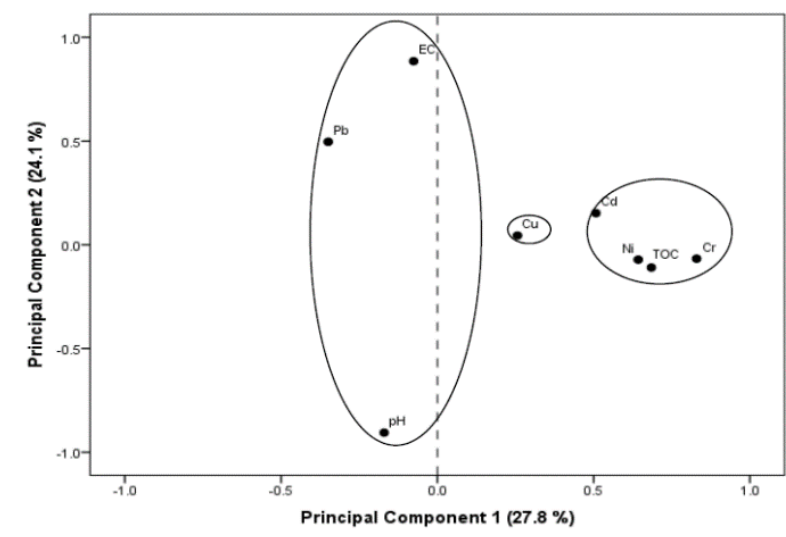

Figure 9. The loading plot of PCA of physicochemical parameters and metals from the study area at depth $0-15 \mathrm{~cm}$

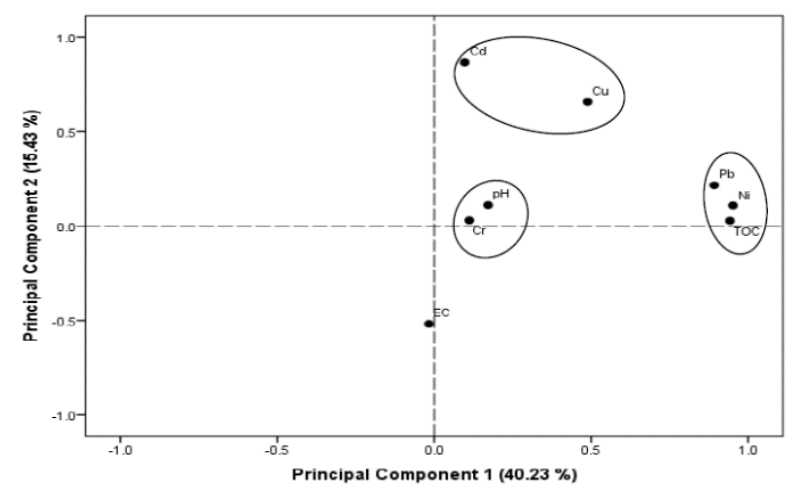

Figure 10. The loading plot of PCA of physicochemical parameters from the study area at depth $15-30 \mathrm{~cm}$. 


\subsection{Lead speciation in soil}

Soil samples with metal concentration greater than their respective regulatory limit was speciated using the fivestep sequential extraction procedure developed by Tessier et al. [20] to assess the bioavailability potential of the metal. In this study, only $\mathrm{Pb}$ concentration exceeded its Nigerian regulatory limit in soil. The concentrations of other metals $(\mathrm{Cd}, \mathrm{Cr}, \mathrm{Ni}$ and $\mathrm{Cu}$ ) studied were within accepted limits. The speciation of these metals was not necessary. The percentage of $\mathrm{Pb}$ in each speciated fraction relative to the total concentration of $\mathrm{Pb}$ is displayed in Fig. 11. Lead was found in all fractions, and the speciation of $\mathrm{Pb}$ in these soils followed the order - SS: Fe-Mn oxides > Exchangeable > Carbonate > Residual > Organic; SE: Residual > Carbonate $>$ Fe-Mn oxide $>$ Organic $>$ Exchangeable; SW: Fe-Mn oxide $>$ Exchangeable $>$ Residual $>$ Organic $>$ Carbonate; NC: Fe-Mn oxide > Residual > Organic > Exchangeable $>$ Carbonate, and NW: Organic $>$ Residual $>\mathrm{Fe}-\mathrm{Mn}$ oxide $>$ Carbonate $>$ Exchangeable.

Lead was fractionated predominantly in the Fe-Mn oxides bound fraction in soils from SS, SW and NC, and midway in soils from SE and NW respectively. The percentage of $\mathrm{Pb}$ in the $\mathrm{Fe}-\mathrm{Mn}$ oxide fraction ranged from 2.16 to $70.7 \%$ with an average of $37.6 \%$ across all studied regions. The high amount of metals in the Fe-Mn fraction of soils was reported to be influenced by high amounts of $\mathrm{Fe}-\mathrm{Mn}$ minerals in soil [33]. A greater amount of $\mathrm{Pb}$ in the $\mathrm{Fe}-\mathrm{Mn}$ oxide fraction could also be as a result of the formation of stable complexes, since these minerals are excellent scavengers for trace metals [34]. High amounts of $\mathrm{Pb}$ in this fraction can thus limit its mobility and bioavailability [35]. This fraction however, is thermodynamically unstable and can be sensitive to reducing conditions and environmental changes (e.g. changes in soil $\mathrm{pH}$ and organic matter), and such changes can lead to redistribution of metals in the available forms [36].

In the residual fraction, $\mathrm{Pb}$ was partitioned predominantly in soils from SE and NW respectively. It ranged from 0.6 to $62.6 \%$, with an average value of $25.2 \%$. The high amounts of $\mathrm{Pb}$ in this fraction indicate little or no serious threat of the metal to human and the surrounding environment, considering the fact that metals in this fraction are not readily environmentally available [37].
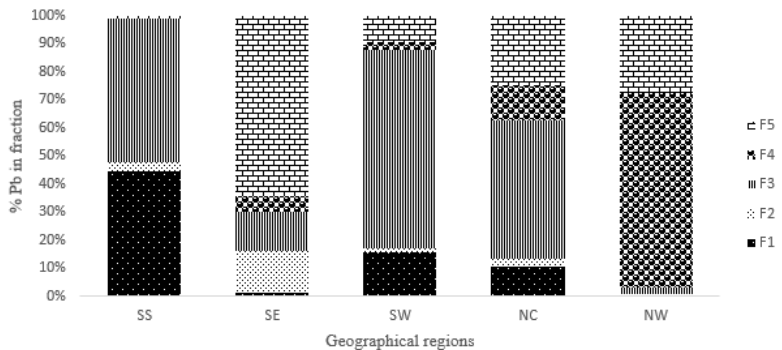

Figure 11. Percentage of $\mathrm{Pb}$ in the various geochemical fractions as a function of total $\mathrm{Pb}$ content in soils (F1-

Exchangeable, F2 - Carbonate bound, F3 - Fe-Mn bound, F4 - Organic bound, F5 - Residual)

The exchangeable form of $\mathrm{Pb}$ ranged from of 0.44 to $46 \%$ with an average of $14.8 \%$. This form is next to the $\mathrm{Fe}-\mathrm{Mn}$ oxide form in SS and SW soils and least in NW soils. Metals in this fraction are in ionic forms; hence, they have a high mobility, can be easily drained by water and are easily released into biota [38]. The strong association of $\mathrm{Pb}$ with this fraction in soils from $\mathrm{SS}$ and $\mathrm{SW}$ calls for concern as $\mathrm{Pb}$ is one of the metals that constitutes the widest possible health risk to humans through plant uptake dietary route $[39,40]$ and direct ingestion of soil particles, especially by children via hand-to-mouth activities.

The percentage of $\mathrm{Pb}$ in the carbonate fraction ranged from 0.64 to $14.1 \%$ with an average of $4.02 \%$. Like the exchangeable fraction, this fraction is also extractable and can accumulate in plants [38]. It is however, observed to be least in soils from SW and $\mathrm{NC}$, and midway in SS and NW soils. The percentage of $\mathrm{Pb}$ in the organic fraction ranged from 0.07 to $72.7 \%$ with an average of $18.7 \%$. Lead in this fraction was observed to be highest in NW soils and low in SS, SW and NW soils. The high and low distributions of $\mathrm{Pb}$ within the organic fraction could be attributed to the corresponding percent total organic carbon recorded in these soils [11, 40, 41].

The overall difference in $\mathrm{Pb}$ distribution among the five fractions is a function of the prevailing soil chemical environment [42]. For instance, the prevailing chemical environment in NW soils was high organic matter, which gave rise to a greater distribution of $\mathrm{Pb}$ in such soils relative to soils with low organic matter while metals associated with $\mathrm{Fe}-\mathrm{Mn}$ oxide fractions can be released under reducing conditions.

\section{Conclusions}

Environmental assessment of soils from CRT disposed areas revealed that:

i. Elemental analysis showed significantly high levels of $\mathrm{Pb}$ in top-soils of all studied regions, indicating that $\mathrm{Pb}$ leaching from discarded CRTs under the action of natural precipitation occurred. The significantly low $\mathrm{Pb}$ levels in sub-soils compared with top-soils suggested a relative absence of leaching down the soil profile. Similarly, the $\mathrm{Pb}$ levels in all top-soils were significantly higher than the control and regulatory limit set by NESREA. However, the concentrations of $\mathrm{Cd}, \mathrm{Cr}, \mathrm{Ni}$ and $\mathrm{Cu}$ were relatively low and within their respective Nigerian regulatory limits.

ii. Geoaccumulation index showed very strong contamination of top-soils with $\mathrm{Pb}$.

iii. The results of elemental analyses and pollution indices summarized above point to the fact that $\mathrm{Pb}$ metal was the major concern arising from open disposal of CRT glass with less environmental impact from the other studied metals.

iv. Sequential extraction results indicated that $\mathrm{Pb}$ was readily bioavailable for surface and ground water as well as biota uptake in SS, SW, NC and NW soils but was of moderate bioavailability in SE soils.

v. The results generally suggest that soils within the vicinity of CRT disposal areas are highly affected by $\mathrm{Pb}$ leachability from the CRTs and the presence of bioavailable $\mathrm{Pb}$ in the studied soils confers toxic characteristic on the soils. Waste CRTs are thus required to be managed in an environmentally sound 
manner to forestall any probable harm to ecological functioning of such areas and to prevent the release of environmentally unstable occluded metals into the available forms.

\section{Funding}

The authors are grateful to the Tertiary Education Trust Fund (TETFund) for Training and Development grant awarded to Paschal O. Iniaghe under the TETFund Academic Staff Training and Development.

\section{Acknowledgement}

The authors appreciate Mr. Eze W. Odali for providing reagents and centrifuge for metal speciation studies.

\section{References}

[1]. J.S.T. Puckett, Exporting harm: the high-tech trashing of Asia. The Basel Action Network. Seattle 7 Silicon Valley Toxics Coalition (2002).

[2]. Solving the E-Waste Problem (StEP) What is ewaste? UNU/StEP initiatives (2012). http://www.stepinitiative.org/index.php/Initiative_WhatIsEwaste.h tml. Accessed January 07, 2016.

[3]. C. LaCoursiere, Electronic Waste Recovery Business (E-120). Business Communication Company (BCC), Norwalk, CT USA (2005).

[4]. J.R. Mueller, M.W. Boehm, C. Drummond, Direction of CRT waste glass processing: Electronics recycling industry communication, Waste Manage 32 (2012) 1560-1565.

[5]. O. Odeyingbo, I. Nnorom, O. Deubzer, R. Kühr, O. Osibanjo, P. Onianwa, G. Adie, S. Adrian, K. Willke, The person-in-the-port project: volumes and quality of used electronics imports into Nigeria, 2016 Electronic Goes Green (EGG) conference, 69 September, Berlin, Germany (2016).

[6]. I.C. Nnorom, O. Osibanjo, M.O.C. Ogwuegbu, Global disposal strategies for cathode ray tubes, Resource Conserv. \& Recycl. 55 (2011) 275-290.

[7]. M. Romic, Bioavailability of trace metals in terrestrial environment: Methodological issues, Eur. Chem. Bulletin 1 (2012) 489-493.

[8]. I.U. Umoren, P.C. Onianwa, Concentrations and distribution of some heavy metals in urban soils of Ibadan, Nigeria, Pakistan J. Sci. \& Ind. Research 48 (2005) 397-403.

[9]. P.O. Oviasogie, E. Omonuji, Levels of heavy metals and physiochemical properties of soil in a foam manufacturing industry, J. Chem. Soc. Nig. 32 (2007) 102-106.

[10]. G. E. Nwajei, C. M. A. Iwegbue, M. I. Okafor, Heavy metals in surface soils under waste dumps from Onitsha, Nig. J. Biolog. Sci. 7 (2007) 405408.

[11]. G.U. Adie, O. Osibanjo, Assessment of soilpollution by slag from an automobile battery manufacturing plant in Nigeria, Afr. J. Environ. Sci. \& Technol. 3 (2009) 239-250.

[12]. S.A. Osakwe, F. Egharevba, Sequential fractionation of cadmium, copper, lead and chromium in soils around municipal solid waste dumps in Agbor, Nigeria, J. Chem. Soc. Nig. 33 (2008) 139-147.

[13]. S.E. Musson, Y.C. Jang, T.G. Townsend, I.H. Chung, Characterization of lead leachability from cathode ray tubes using the toxicity characterization leaching procedure, Environ. Sci. \& Technol. 34 (2000) 4376-4381.

[14]. A. Keith, K. Kessling, K.F. Fitzwater, J. Pichtel, D. Houy, Assessment of $\mathrm{Pb}, \mathrm{Cd}, \mathrm{Cr}$ and $\mathrm{Ag}$ leaching from electronics waste using four extraction methods, J. Environ. Sci. \& Health A43 (2008) 1717-1724.

[15]. T.C. Ling, C.S. Poon, Utilization of recycled glass derived from cathode ray tube glass as fine aggregate in cement mortar, J. Hazard. Mater. 192 (2011) 451-456.

[16]. G.E. Rayment, F.R. Higginson, Australian Handbook of Soil and Water Chemical Methods. Melbourne, Australia: Inkata Press (2002).

[17]. A. Walkley, I.A. Black, An examination of the digestion method for the determination of soil organic matter and a proposed chromic acid titration, Soil Sci. 37 (1934) 29 - 38.

[18]. M. Radojevic, V.M. Bashkin, Practical Environmental Analysis, Royal Society of Chemistry, Cambridge, United Kingdom (1999).

[19]. G. Müller, Index of geoaccumulation in the sediments of the Rhine River, Geojournal 2 (1969) 108-118.

[20]. A. Tessier, P.G.C. Campbell, M. Bisson, Sequential extraction procedure for the speciation of particulate trace metals, Anal. Chem. 51 (1979) 844-851.

[21]. C.M.A. Iwegbue, G.E. Nwajei, O.I. Eguavoen, Impact of land-use patterns on chemical properties of trace elements in soils of rural, semi-urban and urban zones of the Niger Delta, Nigeria, Soil \& Sed. Contam. 21 (2012) 19-30.

[22]. S. Kabiru, R. Yakubu, A. Lukman, T. Akintola, M. Alegbemi, Heavy metal content in soil in Garki Area Council of Federal Capital Territory, Abuja, Nigeria, Biochem. \& Anal. Biochem. 4 (2015) 197.

[23]. M.D. Adesokan, G.U. Adie, O. Osibanjo, Soil pollution by toxic metals near e-waste recycling operations in Ibadan, Nigeria, J. Health \& Prom. 6 (2016) 26-33.

[24]. C.M.A. Iwegbue, C.L. Overah, K. Opuene, E.K. Ossai, G.E. Nwajei, Distribution of metals in urban street dust in Benin City, Pakistan J. Sci. \& Ind. Research 56 (2013) 165-175.

[25]. A. Wali, G. Coinet, M. Khadhraoui, M. Ksibi, Trace metals in surface soil contamination by release of Phosphate industry in the surroundings of SfaxTunisia, Environ. Research, Eng. \& Manage 65 (2013) 20-30.

[26]. O.O. Ojuri, O.A. Taiwo, O.O. Oluwatuyi, Heavy metal migration along a rural highway route: Ilesha -Akure roadside soil, southwestern, Nigeria, Global NEST J. 18 (2016) 742-760.

[27]. National Environmental Standards Regulatory Enforcement Agency (NESREA), Regulations on chemical, pharmaceutical, soaps and detergent 
manufacturing sector; Schedule IV, Regulation 7 Soil quality standards (2009).

[28]. A.A. Chokor, E.O. Ekanem, Heavy Metals Contamination Profile in Soil from Automobile Workshops in Sapele, Nigeria, World J. Anal. Chem. 4 (2016) 26-28.

[29]. K. Bridgen, I. Labunska, D. Santillo, P. Johnston, Chemical contamination at e-waste recycling and disposal site in Accra and Koforidua, Ghana. Greenpeace Research Laboratories Technical Notes 10/2008 (2008). Retrieved from

http://www.greenpeace.org/international/Global/int ernational/planet-2/report/2008/9/chemicalcontamination-at-e-wa.pdf.

[30]. M. Romic, D. Romic D. Dolanjski, I. Stricevic, Heavy metal accumulation in top-soils from wine growing regions, Agric. Conspectus Scientificus 69 (2004) 1-10.

[31]. C.M.A. Iwegbue, S.A. Osakwe, C.I. Elokozie, G. E. Nwajei, Concentrations, human and ecological risks of metals in soils in the vicinity of asphalt in delta State, Nigeria, Jordan J. Earth \& Environ. Sci. 7 (2015) 49-63.

[32]. E.B. Agbaji, S.E. Abechi, S.A. Emmanuel, Assessment of heavy metals level of soil in Kakuri industrial area of Kaduna, Nigeria, J. Sci. Research \& Reports 4 (2015) 68-78.

[33]. E.U. Etim, G.U. Adie, Assessment of toxic heavy metal loading in top-soil samples within the vicinity of a limestone quarry in South Western Nigeria, Afr. J. Environ. Sci. \& Technol. 6 (2012) 322-330.

[34]. P. Kotoky, B.J. Bora, N.K. Baruah, P. Baruah, G.C. Borah, Chemical fractionation of heavy metals in soils around oil installation, Assam, Chemical Speciation \& Bioavail. 15 (2003) 115-125.
[35]. G.O. Adewuyi, M.T. Osobamiro, Chemical speciation and potential mobility of some toxic metals in tropical agricultural soil, Research J. Environ. Toxicol. 10 (2016) 159-165.

[36]. L. Dabrowska, Speciation of heavy metals in sewage sludge after mesophilic and thermophilic anaerobic digestion, Chem. Papers 66 (2012) 598606.

[37]. L.O. Ajala, V.I. Onwukeme, Trace metals speciation in floodplain soil in Enugu Metropolis, Nigeria, J. Appl. Chem. 1 (2012) 9-13.

[38]. S. Shivakumar, S. Srikantaswamy, S. Sreenivasa, B. M. Kiran, Speciation and geochemical behaviour of heavy metals in industrial area soil of Mysore City, India, J. Environ. Protection 3 (2012) 1384-1392.

[39]. A.K. Papafilippaki, M.E. Kotti, G.G. Stavroulakis, Seasonal variation in dissolved heavy metals in the Keritis River, Chania, Greece. Global NEST J. 10 (2008) 320-325.

[40]. L.O. Ajala, V.I. Onwukeme, M.N. Mgbemena, Speciation of some trace metals in floodplain soil of Eke-Mgbom, Afikpo, Nigeria, Am. Chem. Sci. J. 4 (2014) 963-974.

[41]. C.M.A. Iwegbue, G.E. Nwajei, O. Eguavoen, J.E. Ogala, Chemical fractionation of some heavy metals in soil profiles in vicinity of scrap dumps in Warri, Nigeria, Chemical Speciation \& Bioavail. 21 (2009) 99-110.

[42]. V M. Ngole, Using soil heavy metal enrichment and mobility factors to determine potential uptake by vegetables, Plant Soil Environ. 57 (2011) 75-80.

Received: 19.06 .2018

Received in revised form: 26.08.2018

Accepted:05.09.2018 